\title{
Multiple disease genes cause hypertrophic cardiomyopathy
}

\author{
Hugh Watkins
}

Cardiology Division, Brigham and Women's Hospital and Harvard Medical School, Boston, USA and Department of Cardiological Sciences, St George's Hospital Medical School, London $\mathrm{H}$ Watkins

Correspondence to: Dr Hugh Watkins, Department of Genetics Harvard Medical School, 200 Longwood Avenue, Boston, MA 02115, USA.
The clinical features of hypertrophic cardiomyopathy (HCM) are heterogeneous. There is considerable variability in both the morphological manifestations of ventricular hypertrophy ${ }^{12}$ and the prognosis of affected

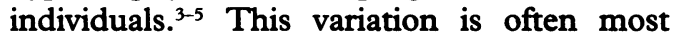
apparent between unrelated families, but intrafamilial heterogeneity may also be quite pronounced. ${ }^{6}$ Sporadic cases widen clinical heterogeneity even further..$^{7-9}$ Despite this, the clinical features of unexplained ventricular hypertrophy and the histological findings of extensive myocyte disarray with interstitial fibrosis ${ }^{10}$ were regarded as sufficiently specific to define a disease. ${ }^{11} 12$ Other phenotypes with some features that overlap with those of "typical" hypertrophic cardiomyopathy have been more difficult to classify clinically. These include apical hypertrophic cardiomyopathy, ${ }^{1314}$ hypertrophic cardiomyopathy of the elderly, ${ }^{15}$ and families with myocyte disarray and sudden death but without hypertrophy. ${ }^{16}$

A more fundamental classification of these clinical entities is becoming possible with the insights provided by molecular genetics. Analyses in familial HCM show that genetic heterogeneity exceeds clinical heterogeneitythat is, hypertrophic cardiomyopathy is genetically not one disease but many. At least four separate disease genes can cause "classic" HCM, indicating greater complexity than might have been expected on clinical grounds. Whether such a genetic classification will be more useful than a clinical one will depend on the extent to which knowledge of the underlying molecular defect helps to predict clinical outcome. In addition knowledge of the underlying molecular defect will assist diagnosis and may provide important insights into the disease process and the potential for intervention.

\section{Genetic analyses}

Because familial hypertrophic cardiomyopathy is inherited as an autosomal dominant mendelian trait, all affected members of a given family must have an identical gene defect. The defect need not be the same in unrelated families with familial HCM, however; either a different mutation within the same gene or a mutation in another gene could be responsible.

MISSENSE MUTATIONS IN THE $\beta$ CARDIAC MHC GENE ARE A MAJOR CAUSE OF HYPERTROPHIC CARDIOMYOPATHY

The $\beta$ cardiac myosin heavy chain (MHC) gene was first implicated as a possible disease gene for HCM by linkage analysis in a single large pedigree in which the disease gene was mapped to chromosome $14 \mathrm{q} 1 .{ }^{17} \mathrm{~A}$ point mutation in the $\beta$ MHC gene that resulted in the substitution of a single amino acid in the myosin polypeptide was subsequently identified in all affected members of this family. ${ }^{18}$ Screening of the $\beta$ cardiac MHC gene in unrelated individuals with familial HCM showed a missense mutation in this gene in up to $50 \%$ of families. ${ }^{19}$ Numerous different missense mutations have been identified (table), all are single nucleotide substitutions resulting in the change of a single amino acid in the

$\beta$ cardiac MHC mutations identified in FHC

\begin{tabular}{|c|c|c|c|c|c|c|}
\hline Amino acid ${ }^{\star}$ & Nucleotide ${ }^{*}$ & Exon & $\begin{array}{l}\text { Change in } \\
\text { charge }\end{array}$ & Survivalt & $\begin{array}{l}\text { Restriction } \ddagger \\
\text { site }\end{array}$ & Reference \\
\hline $\begin{array}{l}\text { Thr124Ile } \\
\text { Arg249Gln } \\
\text { Gly256Glu } \\
\text { Arg403Gln } \\
\text { Arg453Cys } \\
\text { Phe513Cys } \\
\text { Gly584Arg } \\
\text { Val606Met } \\
\text { Lys615Asn } \\
\text { Gly716Arg } \\
\text { Arg719Trp } \\
\text { Arg723Cys } \\
\text { Gly741Arg } \\
\text { Asp778Gly } \\
\text { Leu908Val } \\
\text { Glu924Lys } \\
\text { Glu949Lys }\end{array}$ & $\begin{array}{l}\text { C457T } \\
\text { G832A } \\
\text { G853A } \\
\text { G1294A } \\
\text { C1443T } \\
\text { T1624G } \\
\text { G1836C } \\
\text { G1902A } \\
\text { G1931C } \\
\text { G2232A } \\
\text { C2241T } \\
\text { C2253T } \\
\text { G2307C } \\
\text { A2419G } \\
\text { C2808G } \\
\text { G2856A } \\
\text { G2931A }\end{array}$ & $\begin{array}{r}5 \\
9 \\
9 \\
13 \\
14 \\
15 \\
16 \\
16 \\
16 \\
19 \\
19 \\
20 \\
20 \\
21 \\
23 \\
23 \\
23\end{array}$ & $\begin{array}{r}0 \\
-1 \\
-1 \\
-1 \\
-1 \\
0 \\
+1 \\
0 \\
-1 \\
+1 \\
-1 \\
-1 \\
0 \\
+2 \\
0 \\
+2 \\
+2\end{array}$ & $\begin{array}{l}\text { Intermediate } \\
\text { Poor } \\
\text { Poor } \\
\text { Good } \\
\text { Good } \\
\text { Poor } \\
\text { Good }\end{array}$ & $\begin{array}{l}-E c o \mathrm{RI} \\
+D d e \mathrm{I} \\
-M s p \mathrm{I} \\
+ \text { NlaIII } \\
+S f c \mathrm{I} \\
+B c g \mathrm{I} \\
-P v u \mathrm{II} \\
-D d e \mathrm{I}\end{array}$ & $\begin{array}{l}25 \\
19,20 \\
28 \\
18,19,22,26 \\
19,21,31 \\
30 \\
19 \\
19 \\
24 \\
30 \\
30 \\
23 \\
28 \\
29 \\
22,27 \\
19,23 \\
19\end{array}$ \\
\hline
\end{tabular}

${ }^{\star}$ Mutations are denoted by the normal residue, its position (reference 49 ), and the mutant residue.

†Mutations for which there are sufficient survival data have been classified into categories of good, intermediate, and poor survival of affected individuals.

tChanges in restriction enzyme site are denoted as + for gain in site and - for loss of site. 
globular head or head-rod junction region of the MHC. ${ }^{18-31}$

All of the mutations share certain features that are characteristic of disease-causing missense mutations (as opposed to neutral polymorphisms): there is perfect cosegregation of the presence or absence of the mutation with the disease status of adult individuals; the mutations have been found only in individuals affected with familial HCM and never in unaffected individuals; and the amino acid substitutions affect residues that have been conserved throughout vertebrate evolution, implying particular functional importance. Although these characteristics of the mutations strongly suggest that they are disease causing, they do not exclude the possibility that the $\beta$ MHC mutations are merely polymorphisms linked to an adjacent gene that is itself responsible for the disease. Thus the most conclusive evidence has been the demonstration of newly arising, or de novo, $\beta$ cardiac MHC mutations in individuals with sporadic HCM. ${ }^{23}$ Where a normal copy of the $\beta$ cardiac MHC gene in an unaffected parent acquires a new mutation in an offspring who develops HCM, this cannot be attributed to chance association.

The finding of myosin mutations in sporadic $\mathrm{HCM}$ is one instance where genetic analyses have clarified the clinical classification of the disease-by showing that familial and sporadic forms of $\mathrm{HCM}$ are different parts of a single disease process. In some instances the newly arising $\beta$ MHC mutations that cause sporadic HCM will be transmitted as familial HCM. ${ }^{23}$ This finding has implications for genetic counselling of individuals with sporadic HCM and for assessing their prognosis in the absence of a family history.
OTHER DISEASE GENES FOR FAMIIIAL HCM

Linkage analyses with markers in the region of the $\beta$ cardiac MHC gene identified families in which HCM is not linked to this locus. ${ }^{32-34}$ These findings showed genetic heterogeneity, implying the presence of one or more additional disease gene loci for familial HCM. Direct screening suggests that mutations in the $\beta$ cardiac MHC gene account for less than half of all cases of $\mathrm{HCM},{ }^{1935}$ thus leaving much of the disease unaccounted for. The identification of other disease genes is now an important goal-that is, necessary both for clinical applications and for understanding the pathogenesis of myocardial hypertrophy. So far the chromosomal locations of three further disease loci for familial HCM have been identified by genome-wide searches using linkage analysis.

CMH2-A DISEASE LOCUS ON CHROMOSOME 1q3 A large family was identified with clinical and histological features typical of familial HCM; however, HCM was not caused by a $\beta$ cardiac MHC mutation. ${ }^{36}$ Linkage analyses were performed with highly polymorphic short tandem repeat (STR) sequences, which allow a systematic screening of all chromosomes to look for a polymorphism transmitted with the disease gene. In this way the disease gene in this family was mapped to chromosome 1q3 (fig 1). This new locus was designated CMH2 (cardiomyopathy, hypertrophic, 2) in keeping with HGM 10 nomenclature. ${ }^{37}$

Subsequent linkage analyses in nine smaller families in which HCM was not linked to the $\beta$ MHC gene showed that the disease was linked to the CMH2 locus in two of these families but not in the remaining seven, thus indicating the existence of further familial HCM loci.
Figure 1 Diagrams of the four chromosomes containing known disease gene loci for hypertrophic cardiomyopathy. The disease loci (designated CMH1-4) and relevant genes are identified by arrows (where the gene itself is known) or by square brackets (showing the range of possible map locations). Positions of four other contractile protein genes, previously considered candidate genes for $\mathrm{CMH} 2$ on chromosome 1 , are also shown by square brackets.
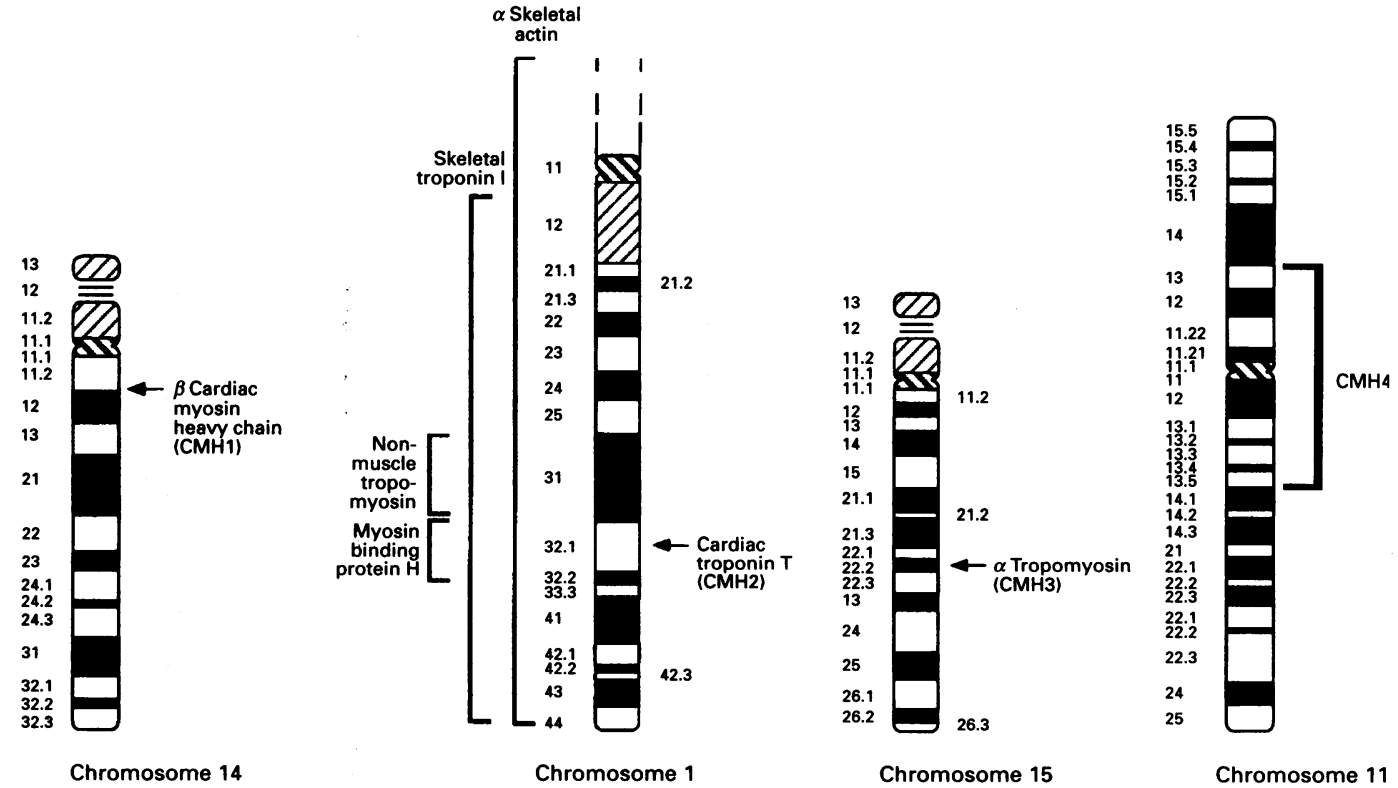
CMH3 - A DISEASE LOCUS ON CHROMOSOME 15q2 Of the families that were not linked to either the $\beta$ cardiac $\mathrm{MHC}$ gene or $\mathrm{CMH} 2$, one was of sufficient size for a further genome-wide search using linkage analysis. ${ }^{38}$ Affected members of this family show a phenotype in which hypertrophy was milder than in typical HCM families with $\beta$ cardiac MHC gene mutations. Penetrance is incomplete in this kindred, with some members without demonstrable hypertrophy passing the condition to offspring. Linkage analysis mapped the disease gene in this family to chromosome 15q2 (fig 1). Of the remaining families known not to be linked to either $\mathrm{CMH} 1$ or $\mathrm{CMH} 2$, two were informative for linkage analyses with chromosome 15q2 markers. Multipoint linkage analyses showed that one of these families was linked to CMH3, while the other was unlinked. This last unlinked family again implied the existence of at least one further disease locus for familial HCM.

CMH4-A DISEASE LOCUS ON CHROMOSOME 11 A fourth disease locus was identified by similar analyses in a single large French family with typical autosomal dominant $\mathrm{HCM}{ }^{39}$ In this family the disease gene was mapped to a region of chromosome 11 (fig 1).

The proportion of HCM that can be attributed to each disease locus is not yet known; nor is it known how many more disease loci there are. The data available suggest that each locus contributes a minority of the total disease prevalence. For example, of five families screened by linkage since the mapping of these disease loci, one was linked to each of $\mathrm{CMH} 1$ and $\mathrm{CMH} 2$, one mapped to the region of $\mathrm{CMH} 4$, the fourth was uninformative, and the fifth appeared unlinked to each of the known loci ( $\mathrm{H}$ Watkins, $\mathrm{H}$ Yeon, and $\mathrm{L}$ Thierfelder, unpublished data). Workers expect that more than one disease locus remains to be mapped; this illustrates the remarkable genetic heterogeneity in this condition.

Many autosomal disorders that were regarded as a single clinical entity have been shown to be caused by mutations in more than one gene ${ }^{4041}$ but few show the extent of genetic heterogeneity now documented in HCM. Perhaps this reflects the relatively crude techniques available to evaluate the phenotype of myocardial hypertrophy that do not distinguish phenocopies (unrelated conditions that mimic each other) as well as they might in other systems. Alternatively, in HCM mutations in related genes may have similar effects because they act through a common pathogenic pathway.

\section{IDENTIFICATION OF THE DISEASE GENES AT} CMH2 AND CMH3: MUTATIONS IN CARDIAC TROPONIN T AND IN $a$ TROPOMYOSIN CAUSE $\mathrm{HCM}$

If a family of related genes underlies the various disease loci then genes for cardiac muscle contractile protein would be the presumed candidates for the $\mathrm{CMH}$ loci. Many components of the thick filaments of striated muscle (for example, myosin light chains) and thin filaments of striated muscle (for examples iso- forms of actin, troponin, or tropomyosin) interact directly or indirectly with the myosin heavy chains and might be involved in a common disease pathway.

Four genes for sarcomeric proteins had been mapped to regions of chromosome 1 that include the CMH2 locus (fig 1): genes encoding $a$ skeletal actin, slow-twitch troponin I, the non-muscle isoform of $a$ tropomyosin, and the human homologue of myosin binding protein- $\mathrm{H}$. These candidate genes at the CMH2 locus have been investigated by the identification of intragenic STR markers to allow precise linkage mapping. Recombination between $\mathrm{CMH} 2$ and the genes encoding skeletal actin and non-muscle tropomyosin excluded these as HCM-causing genes at $\mathrm{CMH} 2$. Though there was no recombination between the slow-twitch troponin I gene or the myosin-binding protein $\mathrm{H}$ gene and $\mathrm{CMH} 2$, analyses of coding sequences did not show abnormalities in affected individuals (H Watkins and C MacRae, unpublished results).

A similar approach was then used to study the $\alpha$ tropomyosin gene as a candidate gene for HCM linked to the CMH3 locus on chromosome 15 on the basis of mapping data in the mouse. Two missense mutations (Asp175Asn and Glu180Gly) in the $a$ tropomyosin gene were shown to cause HCM in the two families previously linked to chromosome $15 \mathrm{q} 2 .{ }^{42}$ These two missense mutations occur in exon 5, which encodes part of a putative binding domain for troponin $T$. These findings supported the model that HCM is a disease of the sarcomere and suggested other thin filament protein genes as candidates for HCM linked to chromosome 1; in particular, cardiac troponin $T$ was specifically implicated.

The previously unmapped gene for cardiac troponin $\mathrm{T}$ was mapped to chromosome 1q by polymerase chain reaction (PCR) amplification of somatic cell hybrids and then shown to be tightly linked to the $\mathrm{CMH} 2$ locus. Mutations in this gene were shown to cause HCM in affected members from three unrelated families. ${ }^{42}$ Two were missense mutations in exons 8 and 9 (Ile79Asn and Arg92Gln, respectively) and the other was a splice site mutation in intron 15 that is predicted to produce a truncated cardiac troponin $\mathrm{T}$ peptide. This mutation in cardiac troponin $T$ is analogous to that found in Drosophila melanogaster upheld ${ }^{2}$, a splice donor mutation that is functionally null because it encodes an unstable peptide. Thus, although most HCM-causing mutations are missense, the splice donor mutation in cardiac troponin $T$ may be functionally null. This suggests that abnormal stoichiometry of sarcomeric proteins can cause cardiac hypertrophy and raises the possibility that an imbalance of sarcomeric proteins can cause secondary forms of cardiac hypertrophy.

\section{Clinical applications}

PRECLINICAL DIAGNOSIS AND MUTATION SCREENING

Because clinical diagnosis of HCM is often 
Figure 2 Kaplan-Meier curves showing the survival of affected individuals with different $\beta$ cardiac myosin missense mutations. Where available, data have been amalgamated from unrelated families with identical mutations.

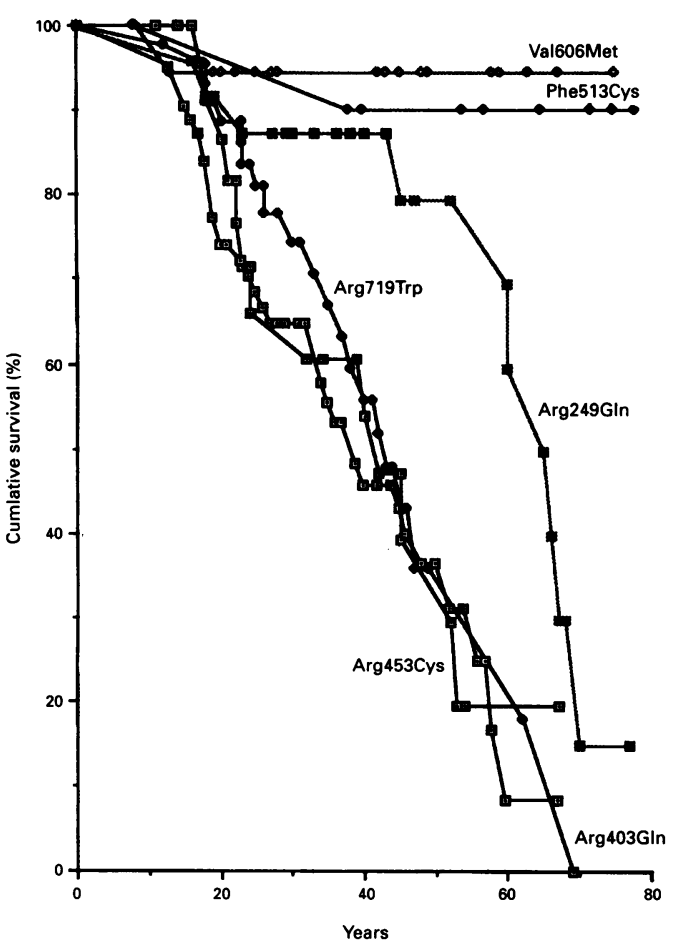

difficult a genetically based diagnosis would offer many advantages. In particular, children who have inherited the disease gene may be at risk of sudden death before the onset of detectable myocardial hypertrophy. Unfortunately, genetic heterogeneity makes preclinical diagnosis more difficult in HCM than in conditions caused by a single or predominant mutation (for example Huntington's chorea ${ }^{43}$ ). To date, genetic diagnosis has only been available for members of families with HCM resulting from $\beta$ MHC mutations. The recent identification of mutations in cardiac troponin $\mathrm{T}$ and $a$ tropomyosin causing HCM, however, will broaden the scope of such genetic testing.

Genetic diagnosis based on identification of $\beta$ MHC mutations is itself complex because of the large variety of mutations causing disease. Some of the mutations have been identified in several families (for example Arg403Gln, Val606Met, and Arg719Trp (table), but many others have only been found in single kindreds. Even within groups of families sharing identical mutations, haplotype analysis has shown instances of independent origin of the mutations rather than a founder effect. ${ }^{31}$ This implies that most mutations that cause HCM have arisen in recent generations, indicating a relatively high new mutation rate for this gene. Thus effective detection requires systematic screening that will detect both known and novel mutations. Several screening techniques have been used to analyse $\beta$ cardiac MHC DNA or CDNA sequences for point mutations, including ribonuclease protection assays, ${ }^{19-21} 2335$ single-strand conformational polymorphism, 2242829 and chemical cleavage of heteroduplexes. ${ }^{30}$

In the initial screening of the $\beta$ cardiac MHC gene the entire coding sequence was screened but no mutations were identified in the coiled rod region. ${ }^{19}$ Subsequent searches for mutations have largely ignored the rod region on the assumption that missense mutations in this region cannot produce the HCM phenotype. Some support for this strategy is provided by linkage data on families in which no mutations were found on screening, showing no evidence of missed mutations. ${ }^{35}$ This implies that, if they occur at all, mutations in the rod causing disease are very infrequent. A single deletion mutation in the terminal portion of the rod has been reported, ${ }^{44}$ but without evidence of segregation with disease. Southern blot analyses in 20 probands with familial HCM did not find other examples of deletion mutations. ${ }^{45}$

The feasibility of preclinical diagnosis has been shown in several kindreds. ${ }^{192226}$ The value of preclinical diagnosis will depend on the success of therapeutic interventions in modifying the disease process or its complications; this potential may be greatest in those individuals without established hypertrophy in whom HCM is diagnosed preclinically. Moreover, trials of treatments can now be performed in homogeneous groups of patients. Preliminary evaluation of interventions should be possible in transgenic mice that carry mutated myosin heavy chain genes; these models would allow testing of both conventional pharmacological treatments and possible genetic manipulations.

Also important will be the degree to which the presence of a particular $\beta$ cardiac MHC mutation predicts the outcome for any individual, especially the risk of sudden death. Does the presence of a $\beta$ cardiac MHC mutation in a child necessarily indicate that important disease will follow? While evaluation of the extent of correlation between phenotype and genotype is undertaken, the implications of preclinical screening programs within families with $\mathrm{HCM}$ will require careful evaluation.

PROGNOSTIC IMPLICATIONS OF SPECIFIC MYOSIN MUTATIONS

The finding of multiple different mutations within the $\beta$ cardiac myosin gene raises the possibility that it is this allelic heterogeneity that determines the wide variation in severity of HCM in unrelated families. The influence of a specific mutation can be determined by studying individuals from unrelated familiessuch that differences in outcome are more likely to relate to the specific mutation that they have in common rather than other genetic or environmental influences. Different branches of single large pedigrees are also adequate for these analyses because in a dominant disease the only genetic material that all affected members will have in common will be the region of the genome carrying the mutation causing the disease.

Phenotype/genotype analyses have not shown clear differences between clinical variables such as the echocardiographic features of hypertrophy, ${ }^{46}$ but there were important differences in the survival of affected individuals. Kaplan-Meier analyses (fig 2) have identified some mutations associated 
with particularly poor prognosis (for example, Arg403Gln, Arg453Cys, and Arg719Trp), with a high incidence of sudden death and significantly shorter survival than is seen with other mutations. ${ }^{1922} 30$

Certain mutations seem to have an intermediate effect on survival (for example, $\operatorname{Arg} 249 \mathrm{G} 1 \mathrm{n},{ }^{19}$ ) while three mutations have been reported to have a particularly good prognosis with near normal survival: Val606Met, ${ }^{19}$ Leu908Val, ${ }^{22}$ and Phe513Cys. ${ }^{30}$ These three mutations differ from others in that they do not involve a net change in charge and so would be predicted to cause less severe disturbance to the structure and function of the myosin polypeptide. It is notable that some of the affected members of three unrelated families with the conservative Val606Met mutation had pronounced ventricular hypertrophy but still tended to survive longer than individuals with other mutations. ${ }^{19}$ These data suggest that the specific myosin mutation is a major determinant of survival and that knowledge of the precise defect may contribute significantly to the identification of those at increased risk of sudden death.

The findings with the three non-charge change mutations suggest that conservative substitutions may in general produce less severe disease. In addition, however, the location of the mutation within the globular head of the myosin polypeptide as well as the change in charge would be expected to determine the impact of each mutation. The tertiary structure of the head region of a myosin polypeptide has recently been established by $x$ ray crystallography. ${ }^{47}$ This allows identification of the location of each $\beta$ cardiac MHC mutation relative to the functional domains and prediction of changes in polypeptide folding and shape in response to particular amino acid substitutions. One striking finding is that the Arg403Gln mutation, which produces the most severe phenotype, is situated in a critical position relative to the cleft involved in actin binding. ${ }^{48}$ This finding was not predicted from the primary structure and so illustrates the potential value of this new data for determining the effects of the mutations causing HCM.

CLINICAL FEATURES OF INDIVIDUALS WITH MUTATIONS IN CARDIAC TROPONIN T AND TROPOMYOSIN

In a disease with three known disease genes, each of which is associated with multiple different mutations, the potential for phenotypic heterogeneity is considerable. For practical purposes it will be important to determine whether it is the disease locus itself or the specific mutation within it that most influences the natural history of hypertrophic cardiomyopathy in a given family.

With the $\beta$ MHC gene locus the range of life expectancies for different mutations is as wide as is seen in the disease as a whole; no clinical features have been identified that distinguish the subgroup of families whose disease is accounted for by mutations in this gene. ${ }^{19} 46$ Preliminary analyses of the other loci also suggest that specific mutations determine outcome and that classification by disease gene alone may not identify clinically distinct subsets. The families selected for the linkage analyses that ultimately identified the troponin $\mathrm{T}$ and $\alpha$ tropomyosin disease genes were chosen for their large size, rather than any phenotypic characteristics. Of the families now shown to have mutations in these genes, only one shows features that make it distinct from the typical range of HCM. One of the families shown to have an $a$ tropomyosin missense mutation has significantly less myocardial hypertrophy than other familial HCM families, with many confirmed gene carriers with normal cross sectional echocardiograms..$^{38}{ }^{42}$ In contrast, affected members of a family with a different $a$ tropomyosin missense mutation have typical hypertrophy. Presumably, then this aspect of the phenotype relates to the particular mutation and is not a general characteristic of $\alpha$ tropomyosin mutations.

INVOLVEMENT OF CMH LOCI IN VARIANTS OF HCM

No family with features of a clinically identifiable variant of HCM has yet been linked to any of the known HCM loci. Two families with apical $\mathrm{HCM}^{13}$ and one with disarray without hypertrophy ${ }^{16}$ have been examined by linkage analysis and do not seem to map to any of the $\mathrm{CMH}$ loci $(\mathrm{H}$ Watkins and L Thierfelder, unpublished data). Similarly, DNA from individuals with these phenotypes and also from individuals with Noonan's syndrome has been screened and no $\beta$ cardiac MHC mutations found ( $H$ Watkins, unpublished data). Together these findings may indicate that such disease entities are genetically distinct from HCM and are the result of mutations in disease genes that are not involved in the pathogenesis of HCM itself.

\section{Conclusions}

The genetics of HCM are revealing a more complex picture than might have been expected on clinical grounds. Three disease genes have now been identified in which mutations result in the same clinical disease entity. These genes encode functionally related components of the cardiac sarcomere: $\beta$ cardiac myosin heavy chain, $a$ tropomyosin, and cardiac troponin T. Further disease genes for HCM exist and are likely also to encode components of the cardiac contractile apparatus. Within each disease gene a variety of mutations is anticipated, resulting in a range of clinical manifestations. Clinical application of genetic diagnosis is likely to remain complex, yet a genetic classification may help to identify subgroups with a different natural history of the disease. Preclinical diagnosis and evaluation of prognosis in association with mutation type, currently limited to those families with mutations in the $\beta$ cardiac MHC gene, can now be extended to the $a$ tropomyosin and cardiac troponin $T$ genes. 
1 Maron BJ, Gottdiener JS, Epstein SE. Patterns and significance of distribution of left ventricular hypertrophy in hypertrophic cardiomyopathy. A wide angle, two dimensional echocardiographic study of 125 patients. $A m f$ Cardiol 1981;48:418-28.

2 Shapiro LM, McKenna WJ. Distribution of left ventricular hypertrophy in hypertrophic cardiomyopathy: a twodimensional echocardiographic study. $\Im \mathrm{Am}$ Coll Cardiol dimensional ech

3 Maron BJ, Lipson LC, Roberts WC, Savage DD, Epstein SE. "Malignant" hypertrophic cardiomyopathy: identification of a subgroup of families with unusually frequent premature death. Am 7 Cardiol 1978;41:1133-40.

4 McKenna W, Deanfield J, Faruqui A, England D, Oakley C, Goodwin J. Prognosis in hypertrophic cardiomyopathy: role of age and clinical, electrocardiographic and hemodynamic features. Am $\mathcal{F}$ Cardiol 1981;47:532-8.

5 Spirito P, Chiarella F, Carratino L, Berisso MZ, Bellotti P, Vecchio C. Clinical course and prognosis of hypertrophic cardiomyopathy in an outpatient population. $N$ Engl $₹$ Med 1989;320:749-55.

6 Ciro E, Nichols PF, Maron BJ. Heterogeneous morphologic expression of genetically transmitted hypertrophic cardiomyopathy: two-dimensional echocardiographic analysis. Circulation 1983;67:1227-33.

7 Frank S, Braunwald E. Idiopathic hypertrophic subaortic stenosis. Clinical analysis of 126 patients with emphasis stenosis. Clinical analysis of 126 patients with emp
on the natural history. Circulation 1968;37:759-88.

8 Maron BJ, Nichols PF, Pickle LW, Wesley YE, Mulvihill J. Patterns of inheritance in hypertrophic cardiomyopathy: assessment by $M$-mode and two-dimensional echocardiography. Am $\mathcal{F}$ Cardiol 1984;53:1087-94.

9 Greaves SC, Roche AHG, Neutze JM, Whitlock RML, Veale AMO. Inheritance of hypertrophic cardiomyopathy: a cross sectional and $M$ mode echocardiographic study of 50 families. Br Heart $\mathcal{f}$ 1987;58:259-66.

10 Davies MJ. The current status of myocardial disarray in hypertrophic cardiomyopathy. $B r$ Heart $f$ 1984;51: 361-3.

11 Maron BJ, Epstein SE. Hypertrophic cardiomyopathy: a discussion of nomenclature. Am 7 Cardiol 1979;43: $1242-4$.

12 Report of the WHO/ISFC task force on the definition and classification of cardiomyopathies. Br Heart $\mathcal{F} 1980 ; 44$ : 672-3.

13 Penas M, Fuster M, Fabregas R, Ilorente C, Cosio FG. Familial apical hypertrophic cardiomyopathy. Am $\dot{f}$ Cardiol 1988:821-2.

14 Yamaguchi H, Ishimura T, Nishiyama S, et al. Hypertrophic nonobstructive cardiomyopathy with giant negative T waves (apical hypertrophy): ventriculographic and echocardiographic features in 30 patients. Am $\mathcal{f}$ Cardiol 1979;44:401-12.

15 Pomerance A, Davies MJ. Pathological features of hypertrophic obstructive cardiomyopathy (HOCM) in the elderly. Br Heart $f$ 1975;37:305-12.

16 McKenna WJ, Stewart JT, Nihoyannopoulos P, McGinty F, Davies MJ. Hypertrophic cardiomyopathy without F, Davies MJ. Hypertrophic cardiomyopathy without hypertrophy: two families with myocardial disarray in the absence of incr
$1990 ; 63: 287-90$

17 Jarcho JA, McKenna W, Pare JA, et al. Mapping a gene for familial hypertrophic cardiomyopathy to chromosome 14q1. N Engl $₹$ Med 1989;321:1372-8.

18 Geisterfer-Lowrance AA, Kass S, Tanigawa G, Vosberg HP, McKenna W, Seidman JG. A molecular basis for familial hypertrophic cardiomyopathy: a beta cardiac myosin heavy chain gene missense mutation. $\mathrm{Cel}$ 1990;62:999-1006.

19 Watkins H, Rosenzweig A, Hwang DS, Levi T, McKenna W, Seidman CE, Seidman JG. Characteristics and prognostic implications of myosin missense mutations in familial hypertrophic cardiomyopathy. $N$ Engl $f$ Med 1992;326:1108-14.

20 Rosenzweig A, Watkins H, Hwang DS, Miri M, McKenna W, Traill TA, et al. Preclinical diagnosis of familial hypertrophic cardiomyopathy by genetic analysis
blood lymphocytes. $N$ Engl $₹$ Med 1991;325:1753-60.

21 Watkins H, Seidman CE, MacRae C, Seidman JG, McKenna W. Progress in familial hypertrophic cardiomyopathy: molecular genetic analyses in the original family studied by Teare. Br Hear $\mathcal{f}$ 1992;67:34-8.

22 Epstein ND, Cohn GM, Cyran F, Fananapazir L. Differences in clinical expression of hypertrophic cardiomyopathy associated with two distinct mutations in the beta-myosin heavy chain gene. A 908Leu- $>$ Val mutation and a 403Arg- > Gln mutation. Circulation 1992;86:345-52.

23 Watkins $H$, Thierfelder L, Hwang DS, McKenna W, Seidman JG, Seidman CE. Sporadic hypertrophic cardiomyopathy due to de novo myosin mutations. $\mathcal{f}$ Clin diomyopathy due to de
Invest 1992;90:1666-71.

24 Nishi H, Kimura A, Harada H, Toshima H, Sasazuki T Novel missense mutation in cardiac beta myosin heavy chain gene found in a Japanese patient with hypertrophic cardiomyopathy. Biochem Biophys Res Commun 1992;

25 Fananapazir L, Dalakas M, Cyran F, Cohn G, Epstein N.
Central core disease is present in hypertrophic cardiomyopathy patients with distinct mutations in the $\beta$ myosin heavy chain gene [abstr]. Circulation 1992;86:I229.

26 Perryman MB, Yu QT, Marian AJ, et al. Expression of a missense mutation in the messenger RNA for betamyosin heavy chain in myocardial tissue in hypertrophic cardiomyopathy. $f$ Clin Invest 1992;90:271-7.

27 Al-Mahdawi S, Chamberlain S, Cleland J, Nihoyannopoulos $\mathrm{P}$, Gilligan D, French J, et al. Identification of a mutation in the $\beta$ cardiac myosin Identification of a mutation in the $\beta$ cardiac myosin myopathy. Br Heart $\mathcal{f} 1993 ; 69: 136-41$.

28 Fananapazir L, Dalakas MC, Cyran F, Cohn F, Epstein $\mathrm{N}$. Missense mutations in the $\beta$ myosin heavy chain gene cause central core disease in hypertrophic cardiomyopathy. Proc Natl Acad Sci USA 1993;90:3993-7.

29 Harada H, Kimura A, Nishi H, Sasazuki T, Toshima H. A missense mutation of cardiac $\beta$-myosin heavy chain gene linked to familial hypertrophic cardiomyopathy in affected Japanese families. Biochem Biophys Res Commun 1993;194:791-8.

30 Anan R, Greve G, Thierfelder L, et al. Prognostic implications of novel $\beta$ cardiac myosin heavy chain gene mutations that cause familial hypertrophic cardiomyopathy. $\mathcal{f}$ Clin Invest 1994;93:280-5.

31 Watkins H, Thierfelder L, Anan R, McKenna WJ, Seidman JG, Seidman CE. Independent origin of identical beta cardiac myosin heavy chain mutations in hypertrophic cardiomyopathy. Am f Hum Genet 1993; hypertrophic

32 Solomon SD, Jarcho JA, McKenna W, et al. Familial hypertrophic cardiomyopathy is a genetically heterogeneous disease. $\mathcal{f}$ Clin Invest 1990;86:993-9.

33 Epstein ND, Fananapazir L, Lin HJ, et al. Evidence of genetic heterogeneity in five kindreds with familial hypertrophic cardiomyopathy. Circulation 1992;85: 635-47.

34 Schwartz K, Beckmann J, Dufour C, et al. Exclusion of cardiac myosin heavy chain and actin gene involvement in hypertrophic cardiomyopathy of several French families. Circ Res 1992;71:3-8.

35 MacRae CA, Watkins $H$, Jarcho JA, et al. An evaluation of RNase protection for the detection of beta cardiac RNase protection for the detection of beta cardiac
myosin heavy chain gene mutations. Circulation 1994; 89:33-5.

36 Watkins H, MacRae C, Thierfelder L, et al. A disease locus for familial hypertrophic cardiomyopathy maps to chromosome 1q3. Nature Genetics 1993;3:333-7.

37 Cox DW, Nakamura Y, Gedde-Dahl T. Report of the committee on the genetic constitution of chromosome 14. Cytogen Cell Genet 1990;55:183-8.

38 Thierfelder L, MacRae C, Watkins $\mathrm{H}$, et al. A familial hypertrophic cardiomyopathy locus maps to chromosome 15q2. Proc Natl Acad Sci USA 1993;90:6270-4.

39 Carrier L, Hengstenberg C, Beckmann JS, et al. Mapping of a novel gene for familial hypertrophic cardiomyopathy to chromosome 11. Nature Genetics 1993;4:311-3.

40 Jordan SA, Farrar GJ, Kumar-Singh R, et al. Autosomal dominant retinitis pigmentosa (adRP;RP6): Cosegregation
of RP6 and the peripherin-RDS locus in a late-onset family of Irish origin. Am $₹$ Hum Genet 1992;50:634-9.

41 Kandt RS, Haines $\mathrm{J}$, Smith $\mathrm{M}$, et al. Linkage of an important gene locus for tuberous sclerosis to a chromosome 16 marker for polycystic kidney disease. Nature Genetics 1992;2:37-41.

42 Thierfelder L, Watkins H, MacRae C, et al. a Tropomyosin and cardiac troponin $T$ mutations cause familial hypertrophic cardiomyopathy: A disease of the sarcomere. Cell 1994;77:701-12.

43 The Huntington's Disease Collaborative Research Group. A novel gene containing a trinucleotide repeat that is expanded and unstable on Huntington's disease chromosomes. Cell 1993;72:971-83.

44 Marian AJ, Yu OT, Mares AJr, Hill $R$, Roberts $R$, Perryman MB. Detection of a new mutation in the beta Perryman MB. Detection of a new mutation in the beta cardiomyopathy. $₹$ Clin Invest 1992;90:2156-65.

45 Tanigawa G, Watkins H, Jarcho JA, Morton CC, Seidman JG, Seidman CE. Absence of major deletions or rearrangements of myosin heavy chain genes in familial hypertrophic cardiomyopathy. Circulation 1993;87(suppl Vii):11-13.

46 Solomon SD, Wolff S, Watkins $\mathrm{H}$, et al. Left ventricular hypertrophy and morphology in familial hypertrophic cardiomyopathy associated with mutations of the betamyosin heavy chain gene. If Am Coll Cardiol 1993;22. 498-505.

47 Rayment I, Rypniewski WR, Schmidt-Base K, et al. Threedimensional structure of myosin subfragment-1: a molecular motor. Science 1993;261:50-8.

48 Rayment I, Holden H, Whittaker M, Yohn CB, Lorenz M, Holmes KC, Milligan RA. Structure of the actin-myosin Holmes KC, Milligan RA. Structure of the actin-myosin
complex and its implications for muscle contraction. complex and its implica

49 Jaenicke T, Diederich KW, Haas W, et al. The complete sequence of the human beta-myosin heavy chain gene and a comparative analysis of its product. Genomics 1990;8:194-206. 